\title{
A Bumpy Border Crossing into the Teaching Culture on a U.S. Campus: Experience of a Chinese Faculty Member
}

\begin{abstract}
Guided by cultural border crossing and teacher identity development theories, this case study explores the bumpy process of a junior Chinese faculty member's border crossing into the U.S. teaching culture and analyzes the challenges, coping strategies, and consequences of his border crossing on teaching and teacher identity development. The study found the subject demonstrated an active process of adaptation during his border crossing and experienced multifaceted and ongoing identity development in which both Chinese culture and the culture that he embraced played important roles in reshaping and facilitating the development of his professional identity, teacher learning, and teaching practices.
\end{abstract}

Keywords Asian faculty, border crossing, teacher identity

\section{Introduction}

The global economy has been flattening the world (Friedman, 2005) through the accumulation and exchange of capital, goods, services, ideas (Green, 2007) and frequent national border crossings of people (Dale \& Robertson, 2003). Consequently, for individuals, cultural adaptation to unknown places is often full of tension, frustration, and conflict, especially when the culture of their home country differs from that of the destination.

\section{Qiang CHENG $(\square)$}

Department of Teacher Education, The University of Mississippi, Oxford, MS 38677, USA E-mail: qcheng@olemiss.edu

Jian WANG

Department of Teaching and Learning, University of Nevada, Las Vegas, NV 89154-3005, USA 
In the US, foreign-born faculty members who were mostly educated in foreign countries and obtained U.S. graduate and/or doctoral degrees comprise an ever increasing number of such border crossers and are changing the composition of U.S. higher education faculty (Foote, Li, Monk, \& Theobald, 2008; National Center for Education Statistics, 2004, 2006, 2008). Among foreign-born faculty members, those from Asian countries are the majority. By 2005, as shown in the report by the National Center for Education Statistics (2008), Asian Americans made up seven percent of all the faculty members in U.S. higher education and most of them were foreign-born Asian faculty members (Lee, 2002).

These foreign-born Asian faculty members are often able to adapt quickly to the research culture of U.S. higher education, showing high research productivity (Kim, Wolf-Wendel, \& Twombly, 2011; Mamiseishvili \& Rosser, 2010). Nonetheless, they often face problems and challenges in integrating into teaching on U.S. campuses (Erickson \& Rodriguez, 1999; Heller, Puff, \& Mills, 1985). Thus, it is important and necessary for educational policy makers and administrators to find resources and provide support for their effective and successful integration into teaching so that the stability, vitality, and productivity of higher educational institutions in sustaining, developing, and creating human knowledge can be maintained and developed (Johnsrud \& Sadao, 1998).

The differences and conflicts between the cultural values that foreign-born Asian faculty members bring with them and the teaching culture into which they are crossing are assumed to be an important challenge for their integration into teaching in U.S. colleges and universities (Collins, 2008). This challenge often fuels the stereotypical view of their instruction as inadequate, which impacts negatively on their professional careers (Johnsrud, 1993; Johnsrud \& Sadao, 1998; Turner \& Thompson, 1993), and thus pushes some foreign-born faculty towards isolation and loneliness (Aguirre, Hernandez, \& Martinez, 1994; Boice, 1993; Olivas, 1988; Stein, 1994).

As we will review specifically later in the empirical section of this paper, empirical research that explores the experiences and the relevant consequences of the integration of foreign-born Asian faculty members into the teaching culture in U.S. higher education institutions is generally underdeveloped (Council for International Exchange of Scholars, 2004; Mayuzumi, 2008; McGowan, 2000; Stanley, 2006). The existing research (e.g., Li \& Beckett, 2006; Kubota, 2002; Kumar, 2002; Rong, 2002) has demonstrated the difficulties that Asian faculty encounter in establishing their authority and credibility in teaching and in the promotion process, in addition to the fact that their identity is pulled in different directions. Relatively few studies investigate different types of challenges that male foreign-born Asian faculty members encounter in the process of integrating into the teaching culture in the US and how the process influences Asian faculty members' professional identity development. This single-case study addresses 
two specific research questions in order to explore the experiences of a Chinese junior faculty member as he entered the U.S. teaching culture: (1) What cultural conflicts and challenges did the Asian faculty experience in his teaching? and (2) How did he deal with these conflicts and challenges?

In the following sections, the theoretical frameworks that guided the design of the study are presented and the relevant empirical literature is reviewed to further justify the focus and questions of the study. Then, the context, data collection and analysis of this study are elaborated and justified. Lastly, we will a present the results along with a discussion of their implications.

\section{Theoretical and Empirical Bases}

\section{Theoretical Frameworks}

This study is framed through two theoretical lenses. The first one is the border crossing theory developed by Anzaldúa (1987) to explain situations in which people move across diverse national, cultural, or geographical boundaries. According to this theory, when people migrate from one culture to another, cultural border crossing inevitably happens (Aikenhead, 1996; Aikenhead \& Jegede, 1999). Tensions arise when border crossers lack a good understanding of the norms of their own culture and those of the cultures whose borders they cross (Magolda, 2001). A smooth cultural border crossing happens when the encountered culture is compatible with the original one, while a challenging border crossing occurs when the two cultures involved are contradictory to each other (Aikenhead \& Jegede, 1999; Phelan, Davidson, \& Cao, 1991).

The cultural border crossing can become more complicated and difficult for the individuals when racial identities are involved (Anzaldúa, 1987; Root, 1996). This is especially the case if the cultural border crossers' ethnicities hold a subordinated and disadvantaged status in society and the dominant and advantaged mainstream lacks compassion and understanding or holds deficit views about the ethnicity of border crossers, whether explicitly or implicitly (Delk, 2006). In the US, race and culture are often interrelated, as individuals of the same racial groups tend to share similar norms and ways of thinking and behaving that define their culture, often resulting in social and economic inequalities along the conflational line of culture and race (Betancourt \& López, 1993; Guion \& Diehl, 2010).

Border crossing and the development of identities are presumably intertwined in a complex and dynamic manner (Spivak, 1995). Border crossers can be trapped into doubting their own identity and be pushed to develop their new identity (Anzaldúa, 1987). A teacher's identity is his or her sense of self as a 
teacher, colored by his or her historical, sociological, psychological, and cultural characteristics (Beijaard, Meijer, \& Verloop, 2004). One's sense of self is a multifaceted lens developed through an active on-going process of reacting, interacting, and negotiating human relationships, social communities, and contexts and thus is interwoven with one's other identities (Beauchamp \& Thomas, 2009; Beijaard et al., 2004; Olsen, 2008). Identity as a teacher defines who one is as a teacher, provides a framework for understanding teaching experiences, and constructing ideas of teaching practice (Assaf, 2008; Sachs, 2005), "which in turn may have a direct or indirect, positive or negative impact on [learners]" (Day, Kington, Stobart, \& Sammons, 2006, p. 611).

Through the lens of the border crossing theory, the authors frame the integration process of a foreign-born Asian male faculty member in this case as one of a cultural border crossing conflated with racial identity. Through the lens of teacher identity theory, the Asian faculty member's experiences of identity conflicts in border crossing is examined. While this theory was originally developed to interpret the process and consequences of school teacher identity conflict and development, the authors see it also useful in interpreting the identity conflict and development that the subject of the study experienced at two levels. At the professional level, his existing teacher identity shaped mostly in his home culture may be incompatible with his identity as a faculty member in the US as the two cultures define the role of a faculty member and ways of working with students in teaching differently. At the racial level, his identity as a former non-minority faculty member in China with traditional Chinese values and his changed status of being a minority immigrant faculty member in the US can be conflictual with each other on the US university campus where the mainstream middle class White cultural values are the most dominant among his colleagues and students. These potential conflicts encountered by the Asian foreign-born faculty member present an especially interesting case for the exploration of the research questions.

\section{Empirical Bases}

To situate the study in the existing empirical literature on foreign-born Asian junior faculty's integration experience into U.S. campus teaching, a thorough search of ERIC, Academic Search Premier, PsycARTICLES, and PsycINFO was conducted using keywords "foreign-born," "Asian faculty," "international faculty," "junior faculty," which led to a few empirical studies. A careful review of these studies contribute to the following two areas of understanding of foreign-born Asian faculty members' integration into U.S. campus cultures.

First, several studies identified the ways in which minority faculty members dealt with the challenges and tensions that they faced as faculty members on U.S. 
campuses and the impact of these challenges and tensions on their identity development, without specifically focusing on teaching. Based on interview data, Richards and Sze (2006) examined one female foreign-born Chinese faculty member's experience in maintaining her dual identities inside and outside her university, and found that the subject experienced a shift of self-identity through her functional adjustment to different situations as she struggled to fight sexism and discrimination in her workplace regarding new faculty promotion. Another two studies used interviews (Sadao, 2003) and autoethnographic narratives (Stanley, 2006) to investigate the factors that contributed to minority faculty members' success, and the challenges in their academic lives. They indicated that minority faculty members including foreign-born Asian faculty members' faced constant tensions from being pulled toward two different identities and, consequently, were often forced to live in two different worlds. In addition, the female Asian faculty were pressured to cope with their students' gender prejudice against them (Manrique, 2002) and face challenges and marginalization in their tenure and promotion process in terms of racism and sexism ( $\mathrm{Li} \&$ Beckett, 2006).

Second, a few studies directly explored the issues related to the discrimination that foreign-born faculty members often faced from both their students and colleagues in teaching. Researchers found that while students accepted the minority faculty who taught courses related to their gender or minority identity (Akindes, 2002; Kumar, 2002; Luthra, 2002) or taught their native language (Kubota, 2002), students often questioned the authority of foreign-born Asian faculty if they taught a language subject other than their native tongues (Kubota, 2002). Using interviews with five foreign-born male junior Chinese faculty, Seagren and Wang (1994, November) found that Chinese faculty members often experienced cultural and linguistic tensions in their teaching. While pressed to adapt to the working environment, they often were not fully accepted, so they felt constant clashes between their own teaching values and the values that came from their campus, resulting in their developing an aloofness in human relationships and linguistic marginality.

Although contributing to the understanding about minority faculty members' identify conflicts and the prejudices that they encountered on U.S. campuses, the existing literature suggests that the border crossing experiences of foreign-born Asian faculty members related to the identity of teaching were underdeveloped and thus, less well understood. Most of these relevant studies failed to either focus on the teaching of foreign faculty members or use multiple data resources to explore their teaching. This single-case study explores a foreign-born Asian faculty member's experiences in adapting to a U.S. campus teaching culture. It is based on both interviews and observation data collected over one semester with a focus on the challenges and tensions as well as the resolutions relevant to his 
teaching identity as he border crossed into a U.S. campus teaching culture.

\section{Research Methodology}

A single-case study is seen as useful for the examination of current incidents or situations that a particular person experiences in a real-life setting that requires various sources of evidence (Yin, 2009). The purpose of such a research methodology is not to generalize the findings. Instead, it is often used to develop a deep and comprehensive understanding about the incidences and situations that one experiences and raise questions for the existing perspectives and interpretations about them (Feagin, Orum, \& Sjoberg, 1991). As an important approach to inquiry, it has been used by psychoanalytic psychologists such as Freud and Breuer, and the founders of behavioral psychology such as Skinner and Watson, in their groundbreaking work that led to new discoveries or theories (Nock, Michel, \& Photos, 2007). These features of a single-case study match the needs of this study to develop a holistical and deep understanding about a foreign-born Asian faculty member's experiences regarding his identity conflicts and the consequences of his identity conflicts in his border crossing in a U.S. university campus environment and consequently, it addresses some of the limitations of the existing theoretical perspectives that are often used to interpret such experiences.

\section{Participant and Contexts of the Study}

The participant, Chen, was born and educated in China with both a Bachelor's and a Master's degree in English Education from a Chinese university. He worked first as a secondary school English teacher and then as a assistant professor of English in a college in China for nearly 20 years. After completing a one-year visiting study and a four-year doctoral program in Urban Education in the US, he became a tenure-track assistant professor of Teacher Education at a public university in a fast-growing metropolitan area in the southwestern US, where white faculty members were dominant but the number of foreign-born Asian faculty members was increasing. At the time of data collection, Chen had just begun his second year of teaching at this institution.

The social, cultural and linguistic contexts of Chen's current teaching were strikingly different from the teaching culture in his home country, which created a border-crossing environment for Chen and pushed him to develop a different identity as a teacher needing a different focus, different strategies, and a different role in his teaching. This situation provided an opportunity for the authors to investigate the research questions using his border crossing experiences.

In China, Chen enjoyed his role in teaching as an authority figure reflecting 
the traditional Chinese cultural values that stress the teacher's authority (shidao zunyan) in his or her classroom (Gu, 2006). However, Chen had to teach the centralized curriculum and be accountable for his students' on the external curriculum-based examinations as identified by several studies on the centralized assessment system and contrived organization of teaching in China (Eckstein, 1993; Wang, 2001). In addition, his teaching effectiveness, whether as a secondary school teacher or a college professor, was also judged by peer observations, critiques, and evaluations that were further influenced by the centralized curriculum and relevant assessments as commonly practiced in many Chinese schools (Paine, Fang, \& Wilson, 2003; Wang \& Paine, 2003). Thus, as a teacher in China, he enjoyed being a knowledge abk authority among students and held his teaching practice and student performance accountable for the curriculum that he was required to teach.

In contrast, at the public U.S. institution where Chen was teaching, faculty members enjoyed great autonomy in deciding what to teach and how to teach, and how to assess their students without being observed and evaluated by colleagues. Faculty's annual and tenure-promotion evaluations of teaching relied heavily on student course evaluation. Due to its content- and construct-related validity, student course evaluation often represents students' feelings about teaching or the teacher more than teaching effectiveness judged by what students have learned (Onwuegbuzie et al., 2007). Additionally, although Chen was assigned a mentor, he was mainly assisted by his mentor on his research work instead of on his teaching as the university was a research-intensive university.

In his border crossing, Chen also experienced a racial identity shift, which provided the authors with an opportunity to examine the research questions under the conflation of culture and race. In China, Chen was a member of the dominant Han ethnic group. The students Chen taught were from the same ethnic background as him. Therefore, he did not have any experience of dealing with racial discrimination and racial inequality in his classrooms or his working environment. By contrast, in the US, his identity had shifted to that of a minority immigrant Chinese surrounded by Caucasian colleagues and students on a campus where racial inequality and misunderstandings could easily exist, both explicitly, and implicitly, and where racial inequality was often used as one of the popular lenses to look at the conflicts and tensions in classrooms.

In addition, in his border crossing, Chen underwent an identity shift from being an experienced competent member of the faculty in English as a Foreign Language to being a junior member of faculty in the process of developing expertise and confidence in teaching and teacher education. In China, he was a competent professor with a Teaching Excellence award because of his confidence and expertise in teaching. However, in the US, in spite of his theoretical knowledge about teaching and teaching methods, and the limited teaching 
assistant experiences that he developed in his doctoral study, he became a "junior" faculty who, unlike many of his peers from the U.S. school and university systems, had neither direct learning experiences at the school and teacher preparation levels or independent teaching experiences in the teacher preparation program in the US as his reference point and support for his new role. Therefore, Chen's situation also provided an important opportunity for the authors to explore the research questions with a subject who was in the process of shifting from being an experienced teacher in one context to an inexperienced faculty member who was re-learning how to teach in a different teaching context.

\section{Data Sources, Collection, and Analysis}

This study included three data sources collected in the fall semester of 2008 when Chen was teaching a general teaching methods course to a group of secondary teacher education students in the early stage of the program. The first data source included two semi-structured interviews with Chen at the beginning and the end of the semester. While the first interview focused on his past experience as a learner, teacher, and professor in China, and the challenges and obstacles that he encountered as a foreign-born faculty member in the US, the second interview focused on the strategies he used to resolve his challenges and problems on the U.S. campus. The two interviews together were designed to gather information about Chen's experience in being challenged to adjust to the teaching culture on U.S. campus.

The second data source consisted of the observations of Chen's teaching over the semester. All 26 class sessions that Chen taught in the semester were observed with detailed field notes written for each class observation. Each class session lasted 75 minutes. Unlike the above interview data, these observed class sessions were not audio recorded. These observation data documented Chen's teaching practice, examples of the actual challenges and obstacles that he encountered in his teaching, and how he coped with these challenges and conflicts.

The third data source involved 10 unstructured brief interviews with Chen before and after class. Although these brief interviews were not audio recorded, careful field notes were written immediately after each interview. These interview data helped researchers solicit Chen's perspectives and verify what was observed in his teaching.

The first and second authors designed the study, interview questions, and its data collection, and all three researchers participated in the process of data analysis. All three authors are all foreign-born Chinese scholars but in different stages of their border-crossing into U.S. teaching culture at the time of the study. The first author was a second-year doctoral student in the Teacher Education 
program, who started to experience border crossing to teaching on the U.S. campus; the second author was a tenured associate professor in Teacher Education, who had a similar background as Chen, experienced, and continued to experience his border crossing into U.S. teaching culture, while the third author was an assistant professor in Teacher Education. These similarities and differences of the authors provided a special lens through which the border crossing and identity change experience of Chen could be critically and thoroughly examined against their own.

The two structured interviews were transcribed and coded to find emerging patterns and themes, which were then grouped into four categories as suggested (Strauss \& Corbin, 1990): (1) Chen's educational background in China and how Chen's beliefs and practice of teaching were developed, (2) Chen's ideas and thoughts about his border-crossing experiences and the challenges that he encountered, (3) how Chen managed his border crossing into the teaching culture on his U.S. campus, and (4) the consequences of his border-crossing experience. Consistent with the emerged themes from the structured interviews, the notes from observations and unstructured interviews were coded and analyzed for specific examples and incidents of each of the four identified themes. The data relevant to the above themes were used as a basis for constructing the backgrounds, vignettes, and interpretations of this case study.

Obviously, this single-case study has its limitations. First, it is limited in generalizing its findings to broader contexts of foreign-born Asian faculty members in different disciplines, at different stages of their professional career work, or in different types of U.S. colleges and universities. Second, our exploration in this study was also limited to Chen's experiences around his teaching and issues of relevance to teaching. His experience outside of teaching such as his professional development could have also contributed to his identify development in the context of his border crossing, but the limited space of this paper prevented researchers from such an examination. Third, no data was collected from students about Chen's teaching and their learning in his class, which mean a more accurate presentation of Chen's teaching, the culture of student learning, and students' thoughts about the documented incidents were not possible. Finally, it is also unknown whether the consequences of his border crossing documented in this study had a temporary or long-term impact on his professional identity as a professor in a U.S. university setting.

In the following section, the authors present three vignettes that emerged from Chen's teaching and analyze how each of these vignettes and the accompanying relevant data from the case address each research question respectively. Although we are unable to represent all the events and experiences that Chen encountered in his border crossing into U.S. teaching culture, these vignettes represent the major issues and themes relevant to our research foci in this case. 


\section{Findings of the Study}

Chen experienced a number of unique challenges in his teaching as a junior faculty member in his border crossing into the culture of teaching in his institution. He struggled with these challenges and was forced to revamp or compromise what he believed was necessary to meet these challenges. The following three vignettes demonstrate his major challenges in his teaching in the semester, how he coped with these challenges, and how his identity development as a junior faculty was affected by his border crossing.

\section{Vignette 1: Can One Do as Villagers Do When Being in a Village?}

Like many foreign-born Asian faculty members, miscommunication and misunderstanding between Chen and his students came up as challenges to his teaching. It is natural for one to assume that the foreign-born faculty members' inability to communicate effectively in English is the cause of such challenges and thus they need to learn as many language skills as possible in order to adapt themselves to the norms of communication popular in their U.S. classrooms. As the Chinese proverb goes, "When you are in the village, do as the villagers do." However, Chen dealt with his challenge in a different manner. Here is an example of the communication challenge that Chen encountered during his teaching and his unique solution to this challenge in the semester.

In one of his class sessions in the middle of the semester, Chen began by informing his students that they would have their class in the computer room next class session because they needed to use computers for creating lesson plans. Chen told the class about the exact location of the computer classroom twice slowly to ensure that everyone in the class knew where to go for the next class session. In spite of his efforts, a middle-aged female student sitting at the back of the classroom demanded that he re-clarify the location of the computer room. It was quite evident that the student's inattention to Chen's repeated announcement prevented her alone from understanding the information. She spoke to Chen so quickly that Chen did not fully understand her and consequently, did not respond to her immediately. The student felt unhappy about Chen's ignoring of her request and said to her neighboring peer angrily in a voice loud enough for everyone in the class to hear, "Never mind, he was just a second language learner." Chen continued his teaching without paying further attention to what the student said as he later revealed that he recognized what the student said was more than her reaction to his language competence.

The student's complaint served multiple purposes. It clearly raised the issue of Chen's problem of language as a foreign-born Asian faculty member. The complaint also effectively hid her inattention in class and shifted blame to the 
instructor. In addition, it challenged Chen's professional preparation for teaching on the U.S. campus by identifying Chen's identity as a second language learner, which made Chen lose face as a teacher. In the unstructured interview with Chen following that class, he indicated that communication served as one of the barriers that prevented him from crossing the complex cultural borders. However, he further explained that this situation might lead students to view him as incompetent in both the English language and teaching in general, and might consequently reinforce the stereotyped image of foreign-born Asian faculty members as poor communicators and thus ineffective teachers. He ignored the student in order to avoid losing face which may have resulted from the embarrassment from the confrontational situation of having been put on the spot about his English. From his point of view, this challenge in language communication was no longer simply an issue of language learning.

In the interview, Chen stressed that it was impossible and ineffective for him to learn the slang and idiomatic phrases that his students used in order to address this challenge. Thus, he encouraged his students to use online postings and emails to communicate with him as such ways of communication would "pose less pressure of instant communication and attend to the students' needs individually." He spent time talking with students individually before and after the class to clarify and confirm his directions and requirements in order to avoid risking "losing face." He also suggested that his students "speak formal English in class" so that he could understand their concerns and questions more easily while at the same time improve his teaching language. In addition, he often shared his Chinese cultural background and Chinese teaching examples with his students in class to encourage students to value him as a Chinese immigrant professor and create opportunities for his students to cross the border toward him professionally.

From Vignette 1 and its analysis, it is clear that Chen understood communication was one of the biggest borders that he must cross. However, to Chen, crossing this border did not mean that he urgently needed to gain language skills. Instead, he chose to improvise his own strategies to overcoming obstacles, allowing him to keep his professional identity intact. In this sense, "When in a village, do as villagers do" does not define his solution to these challenges.

\section{Vignette 2: Can a Monk from a Faraway Temple Preach Better?}

The Chinese proverb, "A monk from a faraway temple preaches better," which is similar to "A prophet is without honor only in his hometown and in his own home" (Matthew 13:57, International Standard Version), suggests that people can improve themselves more effectively by learning from those who are different than from those who are alike. This proverb often reflects the situation in 
Chinese universities, where classrooms are often flooded with Chinese students and faculty members when seminars and lectures are given by foreign scholars or professors. However, when Chen became a faculty member on the U.S. campus, he did not enjoy the same advantage that foreign professors received in China.

In his border crossing into U.S. teaching culture, Chen worked hard to learn the teaching approaches that were popularly applied in the classroom on his campus in spite of the fact that he only knew these approaches conceptually and had little practical experience of using them. Again, his experimentation with these teaching approaches in his classroom created another challenge for his border crossing into U.S. teaching culture. The following vignette showed how he struggled in experimenting with the jigsaw approach and how the application led to unexpected results in his border crossing.

In one of his class sessions in the later part of the semester, after a student completed his scheduled microteaching lesson and peer evaluation, Chen was left with only 35 minutes to help his students understand various approaches to organizing cooperative learning activities. He decided to use the jigsaw approach for the task. Chen briefly introduced some theoretical bases for cooperative learning activities to the class. Then, he divided the class into several expert teams and let each group learn together about one of the cooperative learning approaches. After about 10 minutes, he asked each expert team member to return to their home team to teach the cooperative approach they had learned in their expert team. Finally, he invited a group representative from each expert team to present the assigned approach to the whole class. At the end of the class, several students requested Chen to explain further the cooperative learning approaches since they did not quite yet understand them. Unfortunately, Chen did not have time for the further explanation and had to leave the students with disappointment about their insufficient understanding about the jigsaw approach and its ineffective use in his classroom.

It was clear that his experiment with the jigsaw approach, instead of leading him to see the expected effects on student learning, rather unexpectedly led to his students' frustration. Chen realized clearly that such student frustration resulted from his experimentation with a new teaching strategy with which he was not familiar. If such incidents accumulated, it might gradually erode his self-perception as an effective teacher and diminish his sense of confidence in teaching. As Chen disclosed in the unstructured interview:

The shift of roles in teaching from an authoritative figure to a facilitator challenged me. The language and culture barriers that were entwined with each other surely increased the difficulty level of my cultural adaptation to the U.S. teaching culture.

In addition, Chen claimed that the disappointment of his students that arose 
from his experimentation might naturally have resulted in their providing unfavorable teaching evaluation. The evaluation, as was mentioned earlier, plays a central role in the review of his teaching performance, which would ultimately impact whether he would have a successful career as a faculty member in his institution (Seagren \& Wang, 1994, November).

This vignette suggests that in Chen's efforts to learn to teach effectively, he experienced an uncomfortable and unwilling shift of his teaching identity from a popular and competent professor in his own culture who could deliver lectures effectively to a novice faculty member who had to learn to use more student-centered teaching approaches with little relevant supporting experiences. His conceptual understanding and limited teaching-assistant work in his doctoral program obviously did not support his experiments to the degree he expected. The cost of his teacher learning was clearly reflected in the frustration of his students. This outcome might even lead to students' unsatisfactory evaluation of his teaching performance, and could hinder his professional career.

\section{Vignette 3: Does Bitter Medicine Work?}

Chen used a micro-teaching process to help his students practice important teaching skills and strategies, in which each student teaches a 15 to 20 minute mini-lesson to his or her peers followed by critical feedback and evaluations from Chen and the students. He understood that this process was compatible with both the research (Hiebert, Gallimore, \& Stigler, 2002) and professional standards (National Board for Professional Teaching Standards, 2002) on what and how teachers need to learn to teach. Additionally, this learning activity is consistent with his experiences as a teacher in his home country where teachers' instruction is frequently observed and critiqued by colleagues. He used a Chinese proverb, "Bitter medicine works," to express the value of the role that peer feedback could play in improving one's teaching practice. However, this process faced a serious challenge from the complex culture of teaching and learning on the U.S. campus, as demonstrated in the following vignette.

In one of Chen's mid-semester class sessions, Bill, the only African-American student in the class, was scheduled to teach his mini-lesson. Bill used a PowerPoint to introduce three geographic concepts using relevant pictures and explained the natural environment with pictures of forests, mountains, and rivers, the human environment with photos of houses and buildings, and the adapted environment that blended natural and human environments using images of the Three Gorges Dam in China and the Hoover Dam in the US In the debriefing section, his peers first offered a range of positive comments on Bill's teaching, including how the pictures selected were relevant to the content, how the lesson was well prepared, and how the questions raised were related to real life 
examples. Then, Chen and the class offered several constructive suggestions as follows: His motionless positioning would prevent him from effectively monitoring his students and their interactions; he needed to show more enthusiasm to inspire his students; and he might need to improve eye contact with the students sitting on his right side. Bill sat there apprehensively through this feedback period. Finally, one student suggested that Bill should be mindful of his African-American accent because it would affect students' understanding in his teaching. Immediately Bill stood up and spoke to Chen angrily and loudly, "Dr. Chen, everyone has his or her style." His unexpected words and behavior shocked everyone in the class. Chen kept silent for several seconds, trying to figure out how to respond to this situation. After a short dead silence, Chen wrapped up the mini-lesson activity and moved on to his next teaching task.

In the unstructured interview after the class, Chen stated that stories like that of Bill were uncommon in his teaching experience in China, and this posed a serious challenge to his teaching as an immigrant minority faculty member in a U.S. teacher education classroom. This was especially the case since the majority of the students in his class were Caucasian, which might have influenced the type of English accent to be expected of a teacher candidate. As the only African-American student in Chen's class, Bill seemed to have a very weak position in this conversation. Chen commented on his challenge by saying that U.S. students were not used to peer critique:

Since I had explained to them the role of peer feedback in improving one's teaching using the Chinese proverb, "Bitter medicine works," as a metaphor, I assumed that all my students in my methods class are on the same page in understanding such a role of critique on each other's micro-teaching lessons. If it was in China, students would follow the instructor easily and willingly in such a situation. However, it was not the case here.

He claimed further in the interview that he was caught in the middle of two popular assumptions of teaching among his students. On the one hand, middle class Caucasian English was accepted as the standard language. From this perspective, the student who commented on Bill's accent apparently believed that his accent would prevent students from learning what he taught. On the other hand, one's individual style of teaching was crucial for him or her to be an effective teacher. From this perspective, Bill believed that his accent was one of the important indicators of his individual teaching style that had little to do with student understanding of his teaching.

In addition, Chen explained that Bill's African-American identity further complicated the situation with a potential racial bias that would disqualify him from becoming a teacher by linking his linguistic style to his competence as a teacher, a challenge that Chen himself encountered in his teaching as shown in 
the first vignette. Bill's argumentation could well be an expression of his defiance against racial discrimination using language as documented in different social contexts in the literature (Creese \& Kambere, 2003; Lippi-Green, 1997; Motha, 2006).

Obviously, Chen felt that this complex situation open to different interpretations was especially difficult for him to resolve by sticking to his professional understanding and experiences that were developed in China, not to mention taking the teachable moment to address the social justice issue that could be reflected in the incident when he had no relevant experience or collegial support. As a result, he chose a resolution for survival. As he stated:

Several things came into my mind at that time, and I had a complex feeling. Most importantly, I did not want to make the fire grow which may cause my losing control over the class. So I told myself, "Let me put out the fire first. I do not want to have any trouble now..." At that moment, I was thinking that I'd better not conflict with him (Bill) so I said "OK" to him when I heard his argument. When I wrapped up the microteaching activity, I said to the class, "Anyone who does not feel comfortable about the peer evaluation should let me know before the class. I will adjust the evaluation accordingly in my teaching."

In subsequent microteaching activities in the semester, Chen placed an emphasis on positive comments and encouragement, asked his students not to use sensitive and contentious comments, and persuaded them to be more tolerant of different ideas and approaches to teaching. As he looked back, Chen disclosed that he chose to avoid the spark that could spur a sensitive racial confrontation among his students.

The incidents described in Vignette 3 obviously challenged Chen. He compromised his identity as a professor who would advocate for the application of his professional knowledge and experiences to teacher learning through the "bitter medicine" philosophy. Consequently, he managed to follow the cultural norms of teacher learning that encouraged students' positive experiences, teachers' encouragement, and friendliness in his teacher education classrooms. For Chen, this compromise could help move him closer to the culture of teaching on his campus and avoid the possibility of creating controversial and difficult to resolve situations. It could also help maintain his image as an "effective" teacher in the institutionalized review process of his teaching that depends heavily on his students' feelings about his teaching instead of the professional judgment from his colleagues. In contrast, neither resorting to his professional understanding and experiences nor taking the teachable moment for addressing the issue of social justice would guarantee any immediate successful results. Rather, it could cause continued frustrations and confrontation among his students, which would 
gradually destroy his positive image as a professor in the review process of his tenure and promotion.

\section{Discussion and Conclusion}

As the authors mentioned, the single-case study is limited in developing generalized findings. Thus, the role of this study instead is to raise some issues with the theoretical perspectives often used to interpret the border crossing experience of foreign-born Asian faculty members based on rich data from a faculty member's experience. It is the authors' hope that such a study can function as an inspiration and offer conceptual and methodological references for expanded exploration of the border crossing experiences using multiple cases from the same or different campuses. In spite of the above limitations, this study did generate three findings based on the unique experiences of Chen, each of which extends the existing theoretical and empirical understandings of the challenges and processes that foreign-born Asian faculty members experience in their border crossing into the U.S. teaching culture and consequently, identity shift.

First, in his border crossing, it was difficult or perhaps unnecessary for a foreign-born Asian faculty member like Chen to completely give up his deeply rooted cultural values that were developed in his home country. Sometimes, even if it were possible, it might turn out to be too huge a cost to give up existing cultural values and deeply rooted experiences.

As shown in Vignette 1, Chen could have several options to deal with his language communication barriers. He could spend more of his valuable time and energy on learning and polishing his English language skills, which might gradually lead him to a proficiency level in communication with his students. However, this approach would take the time and energy away from his other responsibilities, such as research and service, which require equal or more investment in terms of energy and time in the junior years of a teaching career. He could also give all his attention to every question and comment regarding where he failed to understand or communicate well in his teaching, which might gradually help him become a more efficient communicator. Nevertheless, his exclusive attention to this issue might require him to forget his deeply rooted cultural value of not losing face in front of his students as a competent teacher and might unfortunately allow for his students' unfair association between his language barriers and inadequate preparation for teaching on a U.S. campus. Considering the complex situation he was in as a foreign-born junior faculty, Chen resorted to a combination of strategies such as using email communications, giving students repeated and reaffirmed directions, sharing with them his 
teaching values and culture, and requesting that they speak formal English rather than slang or informal English. These strategies seemed to ease his communication barriers while allowing him to keep his cultural values intact, as he stated earlier that they "create chances for my students to cross the border" towards him professionally.

This finding extends the existing theoretical and empirical understanding about Asian faculty members' integration into the U.S. teaching culture in several ways. In the existent theoretical literature, the integration is often theorized as a border-crossing process (Aikenhead, 1996) with an implication of straight-line assimilation (Portes \& Zhou, 1993), in which successful border crossers have to acquire all the necessary cultural competencies in the culture of teaching that they are entering while leaving little space for personal agency in reshaping their professional identity actively as well as reconstructing the culture that they are entering (Day et al., 2006; Parkison, 2008; Sfard \& Prusak, 2005). The finding from Chen's case challenges this implication and suggests that in the border crossing, it is possible for one to actively recreate the combination of new strategies that may not exist in the culture of teaching that he or she is entering, which may positively reshape the existing norm of student learning in the culture.

This suggestion resonates with the theoretical argument that, instead of being forced to accommodate to the dominant linguistic and cultural norm of teaching, the language minority faculty members need to value their own cultural and linguistic capital, which could help them create learning opportunities for diversity in their teaching, which in turn not only empower themselves, but also produce opportunities to develop a counter-hegemonic teaching discourse (Nieto, 1999; Kubota, 2002). In this way, the language minority faculty members are creating their comfort zone as a third space for them to dwell in. This finding echoes the assumption of teacher identity theory in that the development of teacher identity is an active process of reacting, interacting, and negotiating with human relationships, social communities, and contexts (Beauchamp \& Thomas, 2009; Beijaard et al., 2004; Olsen, 2008).

The existing empirical studies (Richards \& Sze, 2006; Stanley, 2006) suggest that minority faculty members often develop different value systems compatible with different situations as they move between their university culture and their own community, which often forces them to live in two different worlds. The finding from Chen's case enriches this line of research by suggesting that they may also create new strategies to border crossing with the sources of both their existing cultural values and those in the culture that they are entering (Glick-Schiller, Basch, \& Blanc-Szaton, 1992; Portes, 1997; Portes, Guarnizo, \& Landolt, 1999). Through this process of negotiation, the foreign-born Asian faculty's identity as a professor can be actively reconstructed in relation to his or 
her other identities (Beauchamp \& Thomas, 2009; Beijaard et al., 2004; Olsen, 2008) instead of either following their existing teaching culture and norms or replicating the norms and values of the culture that they are entering. In other words, a hybrid type of identity can be constructed in the border crossing process as a result of negotiating between the two cultures that foreign-born Asian faculty are exposed to. Such reconstruction of teacher identity could ultimately help reshape the dynamics of the teaching culture in the US.

Second, the case of Chen also suggests that when foreign-born Asian faculty members make efforts to be fully immersed in the culture of teaching that they are entering, their confidence and competence as professors in the new culture of teaching could be weakened. As shown in Vignette 2, when Chen was pushed to adopt the teaching strategies compatible with the learning culture of his students without relevant teaching experiences and contextual understanding as his support, his effort proved to be problematic.

This finding confirms the existing theoretical understanding about the consequence of Asian faculty members' full immersion into the culture of teaching on U.S. campuses. As the border crossing theory suggests, the foreign-born Asian faculty's successful border crossing into the U.S. culture of teaching relies heavily on whether or to what extent he or she has acquired the relevant experiences and values compatible with the culture of teaching he or she is entering (Aikenhead \& Jegede, 1999; Phelan et al., 1991). The cultural incongruity in this case might result in one's lowered self-confidence and sense of powerlessness (Richards \& Sze, 2006). This finding from Chen's case supports the above theoretical assumption. In this example, even if Chen made every effort to practice the teaching approaches consistent with the norms of student learning in the culture that he was entering, he failed to attain the expected result because he did not have the congruent experiences and contextual understanding from his existing culture of teaching as the basis for his experiment. This finding is also consistent with the idea of teacher identity theory that the successful development of one's teaching identity should be an ongoing process ultimately related to his or her historical, sociological, psychological, and cultural characteristics (Beijaard et al., 2004).

Third, the case of Chen further suggests that different components of the existing culture of teaching in the US can be inconsistent and in conflict with each other. This situation could help create a niche for the foreign-born Asian faculty member to either hide their struggle in their teaching practice as suggested (Ball \& Cohen, 1996; Little, 1990) or direct their teacher learning on the U.S. campus toward professionally expected results. Vignette 3 clearly documented a situation in which various components of cultural values conflicted with each other. Conflicts occurred between the philosophy of using Standard English and respecting the individual styles such as one's accent. In 
addition, contentions existed between teaching for social justice that is emphasized in the profession and teaching for the institutionalized review process that is required for junior faculty. These conflicts and contentions provided an opportunity for Chen to exercise his strategies for negotiation. In this situation, Chen was clearly being pulled to the norms of student learning and the institutionalized review of his teaching effectiveness, while at the same time drawn to teach as expected by his professional understanding. However, when seeing it become a "no win" situation by moving his teaching into the other direction, he chose to compromise his professional understanding of what his students needed to learn and succumbed to the much more powerful components of his campus culture, the student learning norms and the institution's established review process of his teaching effectiveness. In this process, his professional identity as a professor was reshaped by way of his negotiating.

In spite of the frustrating solution to his challenge by giving up his professional understanding and the opportunity for him to take an active role in addressing social justice issue in his classroom, the above finding from Chen's case does help broaden the existing theoretical and empirical understanding about the culture of teaching when Asian-born faculty members enter practice on a U.S. campus. Following border-crossing theory (Aikenhead, 1996; Anzaldúa, 1987), the culture of teaching that Asian-born faculty members embrace is typically theorized as a coherent unit, which is either in conflict or consistent with the cultural values and experiences that these faculty members bring with them. This framework seems to be useful in guiding a number of empirical studies (Sadao, 2003; Seagren \& Wang, 1994, November; Stanley, 2006) to an important understanding about the tensions between the two cultures that the minority faculty members experienced and had to experience as well as the processes and consequences of these tensions in their border crossing.

However, the finding from Chen's case proposes a challenge for existing interpretations of the teaching culture as a coherent unit with a counter example. As shown in the study, the teaching cultural components on Chen's campus included multiple and complex elements which were not always consistent with each other. This inconsistent nature turned out to become an opportunity for Chen to develop his unique experiences of border crossing and could consequently create different kinds of border crossing experiences for other foreign-born minority faculty members. In the inconsistent and multifaceted teaching culture, we expect reasonably that a foreign-born minority faculty member can strive to create a third place out of their home culture and the culture they are entering into by balancing their different needs. In this place, they can reconstruct a hybrid type of identity to facilitate their professional life on a U.S. campus. Accordingly, the various kinds of professional identities reconstructed by different foreign-born Asian faculty members will surely provide the chance 
for reshaping the existing teaching culture in the US. Using this expanded theoretical assumption as a framework, the opportunities to further extend the existing empirical understanding about the tensions, processes, and consequences of the foreign-born minority faculty members' integration into the culture of teaching on the U.S. campus can certainly be greatly increased.

The above three findings from this study lead the authors to the following directions of research that are worth further exploration. First, research that identifies the patterns, similarities, and differences among their border crossing experiences is necessary in order to develop an extensive understanding about the multiple and complex tensions and processes experienced by foreign-born Asian faculty members who came from different national and cultural backgrounds, work in different institutions, or in different academic fields. Second, it is important to understand how the patterns, similarities, and differences identified in the above border crossing experiences shape teaching practice and their professional identities as U.S. professors. Third, it is necessary to develop a deeper understanding about the different kinds of teaching culture on U.S. campuses and the patterns of cultural conflict within each culture. Finally, it would be interesting to discover how the foreign-born faculty members with established identities from their home country may apply these values and experiences to the reconstruction of their new professional identities and thus meaningfully contribute to reshaping the cultural values and teaching practices in the U.S. campus environment. These lines of research will help draw a more realistic picture of the complex tensions, processes, and consequences of foreign-born minority faculty members' integration into teaching on U.S. campuses, and it will also provide a solid knowledge base for developing sound policies, programs, and practices that support the process of foreign-born minority faculty members who are learning to teach in a new culture.

\section{References}

Aguirre, A., Jr., Hernandez, A., \& Martinez, R. O. (1994). Perceptions of the workplace: Focus on minority women faculty. Initiatives, 56(3), 41-50.

Aikenhead, G. S. (1996). Science education: Border crossing into the subculture of science. Studies in Science Education, 27(1), 1-52.

Aikenhead, G. S., \& Jegede, O. J. (1999). Cross-cultural science education: A cognitive explanation of a cultural phenomenon. Journal of Research in Science Teaching, 36(3), 269-287.

Akindes, F. Y. (2002). The Pacific Asianized other: Teaching unlearning among Midwestern students. In L. Vargas (Ed.), Women faculty of color in the white classroom: Narratives on the pedagogical implications of teacher diversity (pp. 164-181). New York, NY: Peter Lang. 
Anzaldúa, G. (1987). Borderlands/La Frontera: The New Mestiza. San Francisco, CA: Aunt Lute Book Company.

Assaf, L. C. (2008). Professional identity of a reading teacher: Responding to high-stakes testing pressures. Teachers and Teaching: Theory and Practice, 14(3), 239-252. doi: 10.1080/13540600802006137

Ball, D. L., \& Cohen, D. K. (1996). Reform by the book: What is - or might be - the role of curriculum materials in teacher learning and instructional reform? Educational Researcher, 25(9), 6-8, 14.

Beauchamp, C., \& Thomas, L. (2009). Understanding teacher identity: An overview of issues in the literature and implications for teacher education. Cambridge Journal of Education, 39(2), 175-189. doi: 10.1080/03057640902902252

Beijaard, D., Meijer, P., \& Verloop, N. (2004). Reconsidering research on teachers' professional identity. Teaching and Teacher Education, 20(2), 107-128. doi:10.1016/j.tate.2003.07.001

Betancourt, H., \& López, S. R. (1993). The study of culture, ethnicity, and race in American psychology. American Psychologist, 48(6), 629-637.

Boice, R. (1993). New faculty involvement for women and minorities. Research in Higher Education, 34(3), 291-333.

Collins, J. M. (2008). Coming to America: Challenges for faculty coming to United States' universities. Journal of Geography in Higher Education, 32(2), 179-188. doi: $10.1080 / 03098260701731215$

Council for International Exchange of Scholars. (2004). Fulbright new century scholars program. 2005-2006 higher education in the 21st century: Global challenge and national response. Retrieved February 23, 2012, from http://www.cies.org/NCS/2005_2006/

Creese, G., \& Kambere, E. N. (2003). What color is your English? Canadian Review of Sociology and Anthropology, 40(5), 565-573.

Dale, R., \& Robertson, S. (2003). Editorial: Introduction. Globalization, Societies and Education, 1(1), 3-11. doi: 10.1080/1476772032000061789

Day, C., Kington, A., Stobart, G., \& Sammons, P. (2006). The personal and professional selves of teachers: Stable and unstable identities. British Educational Research Journal, 32(4), 601-616. doi: :10.1080/01411920600775316

Delk, J. E. (2006). After the crash: Moving from a discourse of deficit to a discourse of potential. Taboo: The Journal of Culture and Education, 10(1), 121-128.

Eckstein, M. A. (1993). Secondary school examinations: International perspectives on policies and practice. New Haven, CT: Yale University Press.

Erickson, C. D., \& Rodriguez, E. R. (1999). Indiana Jane and the temples of doom: Recommendations for enhancing women and racial/ethnic faculty's success in academia. Innovative Higher Education, 24(2), 149-168. doi: 10.1023/B:IHIE.0000008151.93696.9f

Feagin, J., Orum, A., \& Sjoberg, G. (Eds.). (1991). A case for the case study. Chapel Hill, NC: University of North Carolina Press.

Foote, K. E., Li, W., Monk, J., \& Theobald, R. (2008). Foreign-born scholars in US universities: Issues, concerns, and strategies. Journal of Geography in Higher Education, 32(2), 167-178. doi: 10.1080/03098260701731322

Friedman, T. L. (2005). The world is flat: A brief history of the globalized world in the 21st century. New York, NY: Farrar, Straus and Giroux.

Glick-Schiller, N., Basch, L., \& Blanc-Szanton, G. (1992). Towards a transnational 
perspective on migration: Race, class, ethnicity and nationalism reconsidered. New York, NY: New York Academy of Science.

Green, A. (2007). Globalization and the changing nature of the state in East Asia. Globalization, Societies and Education, 5(1), 23-38.

$\mathrm{Gu}$, M. (2006). An analysis of the impact of traditional Chinese culture on Chinese education. Frontiers of Education in China, 1(2), 169-190. doi: 10.1007/s11516-006-0001-8

Guion, L. A., \& Diehl, D. C. (2010). Enhancing instruction to connect with diverse audiences. Retrieved February 23, 2012, from http://edis.ifas.ufl.edu/fy761

Heller, J. F., Puff, C. R., \& Mills, C. J. (1985). Assessment of the chilly college environment for women. Journal of Higher Education, 56(4), 446-455.

Hiebert, J., Gallimore, R., \& Stigler, J. W. (2002). A knowledge base for the teaching profession: What would it look like and how can we get one? Educational Researcher, 31(5), 3-15. doi: 10.3102/0013189X031005003

Johnsrud, L. K., \& Sadao, K. C. (1998). The common experience of "otherness:" Ethnic and racial minority faculty. The Review of Higher Education, 21(4), 315-342. doi: 10.1353/rhe.1998.0010

Johnsrud, L. K. (1993). Women and minority faculty experiences: Defining and responding to diverse realities. In J. Gainen \& R. Boice (Eds.), Building a diverse faculty: New directions for teaching and learning (pp. 3-16). San Francisco, CA: Jossey-Bass.

Kim, D., Wolf-Wendel, L., \& Twombly, S. (2011). International faculty: Experiences of academic life and productivity in U.S. universities. The Journal of Higher Education, 82(6), 720-747. doi: $10.1353 /$ jhe.2011.0038

Kubota, R. (2002). Marginality as an asset: Toward a counter-hegemonic pedagogy for diversity. In L. Vargas (Ed.), Women faculty of color in the white classroom: Narratives on the pedagogical implications of teacher diversity (pp. 293-307). New York, NY: Peter Lang.

Kumar, P. (2002). Yellow lotus in White lily pond: An Asian American woman teaching in Utah. In L. Vargas (Ed.), Women faculty of color in the white classroom: Narratives on the pedagogical implications of teacher diversity (pp. 278-291). New York, NY: Peter Lang.

Lee, S. M. (2002). Do Asian American faculty face a glass ceiling in higher education? American Educational Research Journal, 39(3), 695-724. doi: $10.3102 / 00028312039003695$

Li, G., \& Beckett, G. H. (Eds.). (2006). "Strangers" of the academy: Asian women scholars in higher education. Sterling, VA: Stylus.

Lippi-Green, R. (1997). English with an accent: Language, ideology, and discrimination in the United States. London, UK: Routledge.

Little, J. W. (1990). The persistence of privacy: Autonomy and initiative in teachers' professional relationship. Teachers College Record, 91(4), 509-536.

Luthra, R. (2002). Negotiating the minefield: Practicing transformative pedagogy as a teacher of color in a classroom climate of suspicion. In L. Vargas (Ed.), Women faculty of color in the white classroom: Narratives on the pedagogical implications of teacher diversity (pp. 109-122). New York, NY: Peter Lang.

Magolda, P. (2001). Border crossing: Collaboration struggles in education. The Journal of Educational Research, 94(6), 346-358.

Mamiseishvili, K., \& Rosser, V. J. (2010). International and citizen faculty in the United States: An examination of their productivity at research universities. Research in Higher Education, 
51(1), 88-107. doi: 10.1007/s11162-009-9145-8

Manrique, C. G. (2002). A foreign woman faculty's multiple whammies. In L. Vargas (Ed.), Women faculty of color in the white classroom: Narratives on the pedagogical implications of teacher diversity (pp. 146-162). New York, NY: Peter Lang.

Mayuzumi, K. (2008). "In-between" Asia and the West: Asian women faculty in the transnational context. Race, Ethnicity and Education, 11(2), 167-182.

McGowan, J. M. (2000). African-American faculty classroom teaching experiences in predominantly White colleges and universities. Multicultural Education, 8(2), 19-22.

Motha, S. (2006). Racializing ESOL teacher identities in U.S. K-12 public schools. TESOL Quarterly, 40(3), 495-518.

National Board for Professional Teaching Standards. (2002). What teachers should know and be able to do. Arlington, VA: National Office of National Board for Professional Teaching Standards.

National Center for Education Statistics. (2004). Digest of education statistics, 2003. Washington, DC: U.S. Department of Education, Institute for Education Sciences.

National Center for Education Statistics. (2006). Digest of education statistics, 2005. Washington, DC: U.S. Department of Education, Institute for Education Sciences.

National Center for Education Statistics. (2008). Digest of education statistics, 2007. Washington, DC: U.S. Department of Education, Institute for Education Sciences.

Nieto, S. (1999). The light in their eyes: Creating multicultural learning communities. New York, NY: Teachers College.

Nock, M. K., Michel, B. D., \& Photos, V. I. (2007). Single-case research designs. In D. McKay (Ed.), Handbook of research methods in abnormal and clinical psychology (pp. 337-350). Thousand Oaks, CA: Sage.

Olivas, M. A. (1988). Latino faculty at the border: Increasing numbers key to more Hispanic access. Change, 20(3), 6-9.

Olsen, B. (2008). Teaching what they learn, learning what they live: How teachers' personal histories shape their professional development. Boulder, CO: Paradigm.

Onwuegbuzie, A. J., Witcher, A. E., Collins, K. M. T., Filer, J. D., Wiedmaier, C. D., \& Moore, C. W. (2007). Students' perceptions of characteristics of effective college teachers: A validity study of a teaching evaluation form using a mixed-methods analysis. American Educational Research Journal, 44(1), 113-160. doi: 10.3102/0002831206298169

Paine, L., Fang, Y., \& Wilson, S. (2003). Entering a culture of teaching: Teacher induction in Shanghai. In E. Britton, L. Paine, D. Pimm \& S. Raizen (Eds.), Comprehensive teacher induction: Systems for early career learning (pp. 20-82). Dordrecht, Netherlands: Kluwer Academic Publishers.

Parkison, P. (2008). Space for performing teacher identity: Through the lens of Kafka and Hegel. Teachers and Teaching: Theory and Practice, 14(1), 51-60. doi: 10.1080/13540600701837640

Phelan, P., Davidson, A. L., \& Cao, H. T. (1991). Students' multiple worlds: Negotiating the boundaries of family, peer, and school cultures. Anthropology and Education Quarterly, 22(3), 224-250.

Portes, A. (1997). Immigration theory for a new century: Some problems and opportunities. The International Migration Review, 31(4), 799-825.

Portes, A., \& Zhou, M. (1993). The new second generation: Segmented assimilation and its variants. The Annals of the American Academy of Political and Social Science, 530(1), 
74-96.

Portes, A., Guamizo, L. E., \& Landolt, P. (1999). The study of transnationalism: Pitfalls and promise of an emergent research field. Ethnic and Racial Studies, 22(2), 217-237.

Richards, E., \& Sze, S. (2006). East meets west: Teaching the elite on both sides of the pacific. Retrieved February 23, 2012, from ERIC database (ED491504).

Rong, X. L. (2002). Teaching with differences and for differences: Reflections of a Chinese American teacher educator. In L. Vargas (Ed.), Women faculty of color in the white classroom: Narratives on the pedagogical implications of teacher diversity (pp. 125-144). New York, NY: Peter Lang.

Root, M. P. P. (Ed.). (1996). The multiracial experience: Racial borders as the new frontier. Thousand Oaks, CA: Sage Publications.

Sachs, J. (2005). Teacher education and the development of professional identity: Learning to be a teacher. In P. M. Denicolo \& M. Kompf (Eds.), Connecting policy and practice: Challenges for teaching and learning in schools and universities (pp. 5-21). Oxford, UK: Routledge.

Sadao, K. C. (2003). Living in two worlds: Success and bicultural faculty of color. The Review of Higher Education, 26(4), 397-418.

Seagren, A. T., \& Wang, H. (1994, November). Marginal men on an American campus: A case of Chinese faculty. Paper presented at the 19th Annual Meeting of the Association for the Study of Higher Education, Tucson, AZ.

Sfard, A., \& Prusak, A. (2005). Telling identities: In search of an analytic tool for investigating learning as a culturally shaped activity. Educational Researcher, 34(4), 14-22. doi: 10.3102/0013189X034004014

Spivak, G. C. (1995). Can the subaltern speak? In B. Ashcroft, G. Griffiths, \& H. Tiffin (Eds.), The post-colonial studies reader (pp. 24-28). London, UK: Routledge.

Stanley, C. A. (2006). Coloring the academic landscape: Faculty of color breaking the silence in predominantly white colleges and universities. American Educational Research Journal, 43(4), 701-736. doi: 10.3102/00028312043004701

Stein, W. (1994). The survival of American Indian faculty. Thought and Action: The National Education Association Higher Education Journal, 10(1), 101-113.

Strauss, A., \& Corbin, J. (1990). Basics of qualitative research: Grounded theory procedures and techniques. New York, NY: Sage.

Turner, C. S., \& Thompson, J. R. (1993). Socializing women doctoral students: Minority and majority experiences. The Review of Higher Education, 16(3), 355-370.

Wang, J. (2001). Contexts of mentoring and opportunities for learning to teach: A comparative study of mentoring practice. Teaching and Teacher Education, 17(1), 51-73. doi: 10.1016/S0742-051X(00)00038-X

Wang, J., \& Paine, L. W. (2003). Learning to teach with mandated curriculum and public examination of teaching as contexts. Teaching and Teacher Education, 19(1), 75-94. doi: 10.1016/S0742-051X(02)00087-2

Yin, R. K. (2009). Case study research: Design and methods (4th ed.). Los Angeles, CA: Sage. 